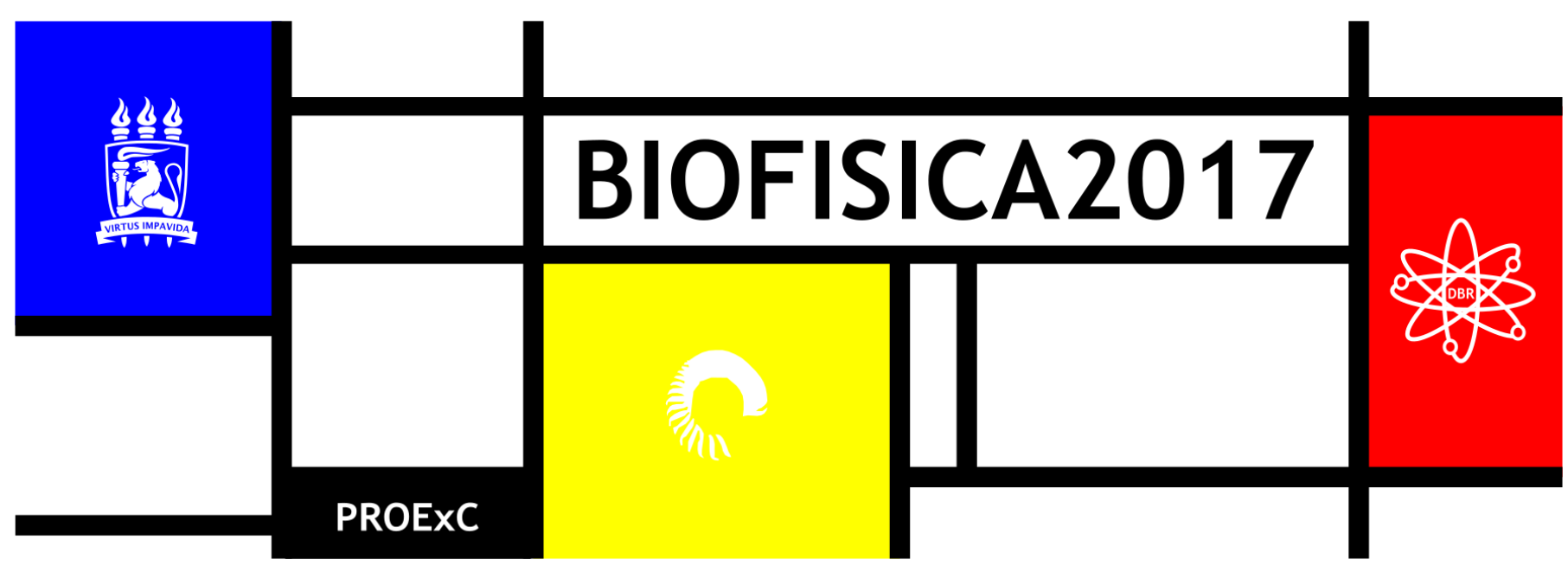

\title{
MONITORIA SUPLEMENTA OU COMPLEMENTA A DOCÊNCIA? EXPERIÊNCIAS NA DISCIPLINA INTRODUÇÃO A FÍSICA
}

\author{
Mayara Lopes de Freitas Lima ${ }^{1 *}$, Adriana Fontes ${ }^{2}$, Otacílio Antunes Santana ${ }^{1}$ \\ ${ }^{1}$ Grupo de Pesquisa Educometria/CNPq, DBR/CB/UFPE; ${ }^{2}$ Laboratório de Biofísica-Química/ DBR/CB/UFPE \\ *mayfreitas18@gmail.com
}

\section{INTRODUÇÃO}

A Monitoria é um programa institucional das Universidades Federais e de outras instituições, que seleciona, através de editais específicos, alunos vinculados à instituição que já cursaram determinadas disciplinas, para auxiliarem o docente no planejamento, execução e avaliação de suas aulas. As finalidades do monitor no programa são: fortalecer a comunicação e relação docente-discente, acompanhar o ritmo de aprendizagem dos alunos em conteúdo e cumprimento do cronograma, e institucionalmente, auxiliar na melhora do desempenho acadêmico dos cursos de graduação e servir de ponte para os alunos em atividades de pesquisa e extensão (relação teoria-prática). Essas atividades certificam o monitor curricularmente e o qualificam para uma possível carreira docente.

Além desses intentos, a literatura apresenta diversas vantagens de uma disciplina ter um monitor, pois ele traz uma narrativa nova na relação docente-discente, é de uma geração aproximadamente dos alunos cursistas, e se identifica (monitor-alunos cursistas) na linguagem, no comportamento, na semiótica, nos saberes tecnológicos, nas relações sociais virtuais, e na possível dificuldade com o aprendizado do conteúdo (HAAG et al. 2008; ESKENAZI; MARTINS; FERREIRA JUNIOR, 2013; GARCIA; SILVA FILHO; SILVA, 2013; DANTAS, 2014; SANTOS et al. 2015; FRISON, 2016).

0 monitor ao longo do percurso da monitoria precisa tomar posse dos saberes docentes para aplicar e refletir sobre a teoria (techné), a práxis e a poesia (poiesis) da pratica educativa (FREIRE, 2002). Paulo Freire no livro "Pedagogia da Autonomia", descreveu 27 saberes necessários à prática educativa que envolvem essas três vertentes. Se o docente eventualmente necessita de um monitor, então, o monitor complementaria ou suplementaria a prática do docente em relação aos saberes? Para efeito de conceituação nesse trabalho "complementar" significa acrescentar o que está insuficiente e "suplementar" é acrescentar acima do suficiente. 0 monitor seria um didático ou paradidático? Responder essas questões foi o objetivo desse trabalho em uma disciplina obrigatória de um curso de graduação.

\section{MÉTODOS E ANÁLISES}

Dez turmas da disciplina 'Introdução à Física', obrigatória para o curso de Licenciatura em Ciências Biológicas, da Universidade
Federal de Pernambuco, foram analisadas de 2011 a 2015, no qual cada turma foi denominada pelos seus respectivos semestres: 2011.1, 2011.2, 2012.1, 2012.2, 2013.1, 2013.2, 2014.1, 2014.2 e 2015.1 e 2015.2 .

As duas primeiras turmas (2011.1 e 2012.2) não tiveram acompanhamento de monitores, e o restante das turmas, ao contrário, tiveram a presença de monitor.

Ao final de cada turma, foi quantificada a porcentagem dos alunos que foram reprovados (com a realização da avaliação final), reprovados por falta, aprovados por média (sem a realização da avaliação final), e aprovados (com a realização das avaliações finais, ou seja, não conseguiu durante as avaliações, uma média superior a 7,0). Dois grupos amostrais foram estabelecidos, para efeito de comparação estatística (Teste Qui-Quadrado), as turmas sem monitoria e com monitoria.

Nas turmas com monitoria (2012.1, 2012.2, 2013.1, 2013.2, 2014.1, 2014.2 e 2015.1 e 2015.2 ) os alunos classificaram, através de um questionário, em uma escala Likert de 1 a 10 (SANTANA, 2014), o quanto na escala (1 não aplica e 10 aplica totalmente) o docente ou o monitor aplicou em sua atividade os saberes necessários a práticas educativas (FREIRE, 2002): 1) Rigorosidade metódica; 2) Pesquisa; 3) Respeito aos saberes dos educandos; 4) Criticidade; 5) Estética e ética; 6) Corporeificação das palavras pelo exemplo; 7) Risco, aceitação do novo e rejeição a discriminação; 8) Reflexão crítica sobre a prática; 9) Reconhecimento e a assunção da identidade cultural; 10) Consciência do inacabado; 11) Reconhecimento de ser condicionado; 12) Respeito à autonomia do ser do educando; 13) Bom senso; 14) Humildade, tolerância e luta em defesa dos direitos dos educadores; 15) Apreensão da realidade; 16) Alegria e esperança; 17) Convicção de que a mudança é possível; 18) Curiosidade; 19) Segurança, competência profissional e generosidade; 20) Comprometimento; 21) Compreender que a educação é uma forma de intervenção no mundo; 22) Liberdade a autoridade; 23) Tomada consciente de decisões; 24) Saber escutar; 25) Reconhecer que a educação é ideológica; 26) Disponibilidade para o diálogo; e 27) Querer bem aos educandos. Outra questão foi aplicada aos alunos da turma: o que se espera de um 'bom monitor'? As respostas foram compiladas em 'nuvens de palavras', das palavras-chave mais citadas nas respostas (SANTANA, 2016). 


\section{RESULTADOS E DISCUSSÃO}

$\mathrm{Na}$ comparação das turmas com e sem monitoria, houve uma diferença significativa entre esses dois grupos amostrais ( $p<$ 0,001 ). Porém, quando se verifica os dados (Figura 1), as turmas sem monitoria tiveram um maior número de aprovados em porcentagem. Na segmentação de qual a forma de aprovação (se por média ou por avaliação final) o grupo amostral com monitoria obteve uma maior aprovação com avaliação final (39\%) do que a turma sem monitoria (27\%). Avaliar esse dado é importante, pois os alunos que tiveram que realizar a avaliação final foram os que mais requisitaram ajuda ao monitor, e quando tinham a presença do monitor, maior foi a aprovação. Os alunos que foram aprovados diretamente por média e os reprovados (tanto pela avaliação quanto por falta) foram aqueles que em geral não requisitaram as atividades de monitoria, ou seja, foram indiferentes à presença ou à ausência do monitor na disciplina.

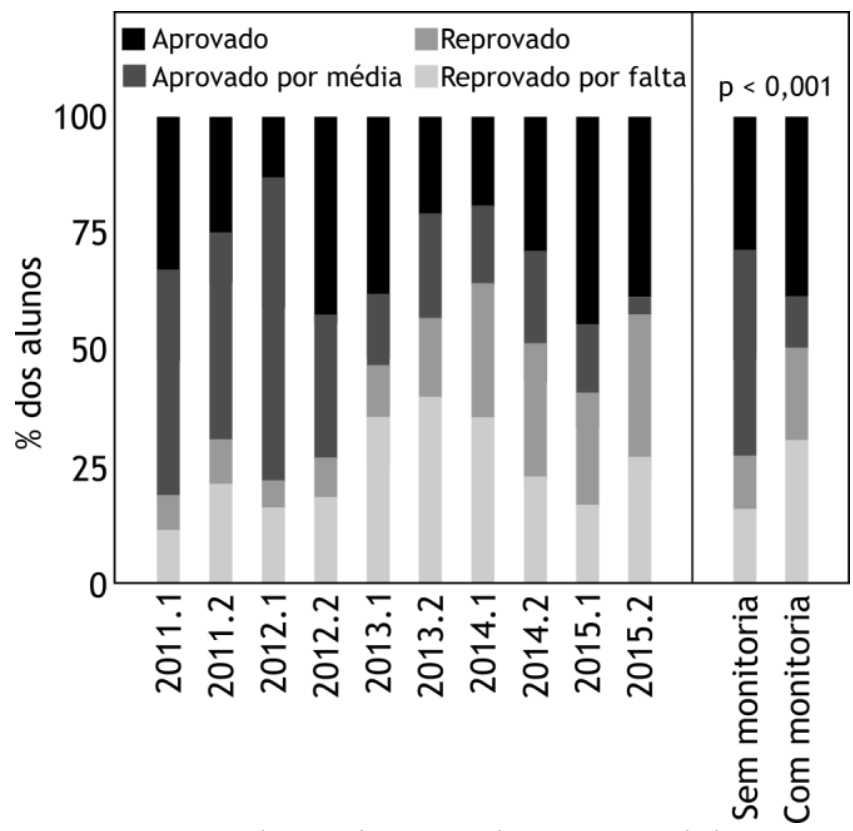

Figura 1. Porcentagem de aprovados e reprovados nas turmas avaliadas com e sem monitoria.

Para os que necessitaram e requisitaram o monitor, foi evidenciado que os alunos procuravam no monitor, além da compreensão do conteúdo e articulação teoria e prática, alguma qualificação que foi insuficiente ao docente na mediação no processo de ensino e aprendizagem (SANTANA, 2014). Isso foi certificado quando questionado aos estudantes das turmas com monitoria qual o peso que dariam ao docente e ao monitor em relação à aplicação dos saberes necessários à prática docente. Saberes relacionados a relação docente-discentes foram os que os monitores tiveram maiores distâncias nos pesos (>4), para cima, do que os docentes (Figura 2), tais como: 'Saber escutar' e 'Disponibilidade para o diálogo". Esses saberes podem refletir a contemporaneidade de geração entre o monitor e os alunos, também notado pelos pesos dados ao docente e ao monitor na aplicação do saber 'Reconhecimento e a assunção da identidade cultural' e 'Risco, aceitação do novo e rejeição à discriminação'.

Os docentes tiveram os pesos maiores em saberes como 'Rigorosidade metódica', 'Segurança, competência profissional e generosidade', 'Tomada consciente de decisões' e 'Comprometimento', saberes que refletem a preocupação conteudista e da construção de competências profissionais pelo docente.

As atribuições básicas do monitor, sintetizadas da literatura (DANTAS, 2014; FRISON, 2016), caminham na direção dos dados desse trabalho: i) articular o contato entre o docente e aluno (pessoalmente e por redes sociais), ii) acompanhar os alunos em relação ao seu ritmo frente ao conteúdo e cronograma, iii) realizar plantões de dúvidas, iv) ajudar em atividades de estudos dirigidos, e v) apoiar o docente nos dias das avaliações presenciais. O monitor é um complemento do docente, não com prioridade no conteúdo (o docente já articula competentemente essa vertente), mas, com prioridade na relação paradidática do conteúdo (práxis e poiesis). O paradidatismo foca na contextualização espacial, temporal e social, na simulação, na discussão dos cenários (habitats), nos atores, no figurino (na semiótica), no ambiente de laboro (biossegurança e ergonomia), na exceção ('ponto fora da curva'), nas vivências e narrativas, no abstrato (e.g. metafísica) e no engajamento sobre a temática da disciplina.

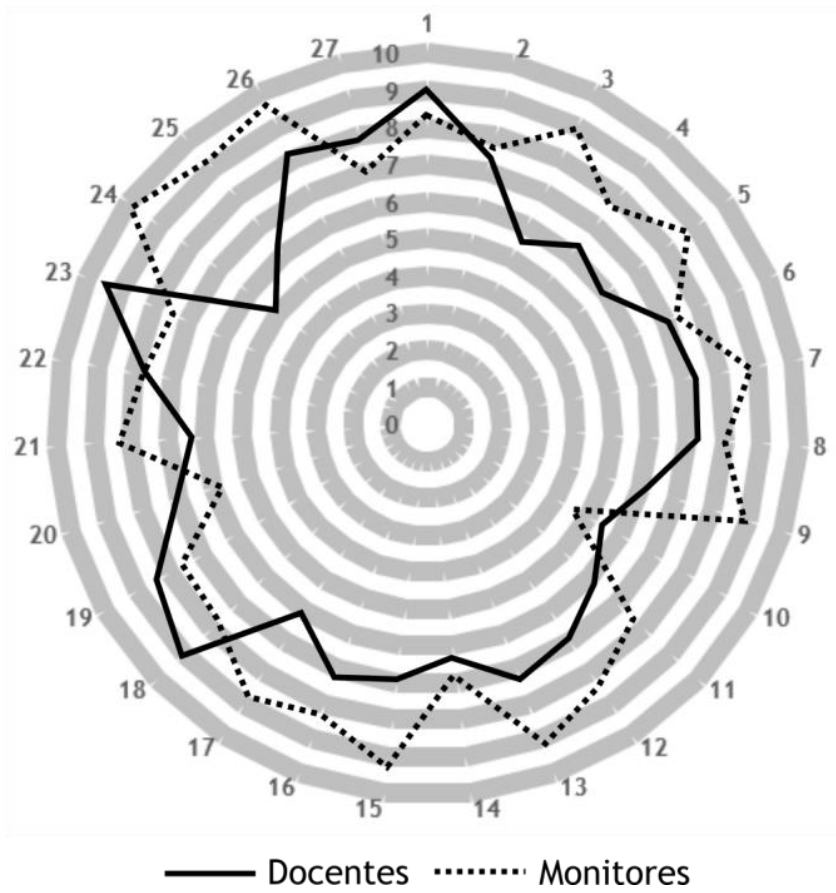

Figura 2. 0 quanto em uma escala Likert de 1 a 10 (1 não aplica e 10 aplica totalmente) o docente ou monitor aplica os 27 saberes necessários à prática educativa (FREIRE, 2002; SANTANA, 2014): 1) Rigorosidade metódica; 2) Pesquisa; 3) Respeito aos saberes dos educandos; 4) Criticidade; 5) Estética e ética; 6) Corporeificação das palavras pelo exemplo; 7) Risco, aceitação do novo e rejeição a discriminação; 8) Reflexão crítica sobre a prática; 9) Reconhecimento e a assunção da identidade cultural; 10) Consciência do inacabado; 11) Reconhecimento de ser condicionado; 12) Respeito à autonomia do ser do educando; 13) Bom senso; 14) Humildade, tolerância e luta em defesa dos direitos dos educadores; 15) Apreensão da realidade; 16) Alegria e esperança; 17) Convicção de que a mudança é possível; 18) Curiosidade; 19) Segurança, competência profissional e generosidade; 20) Comprometimento; 21) Compreender que a educação é uma forma de intervenção no mundo; 22) Liberdade a autoridade; 23) Tomada consciente de decisões; 24) Saber escutar; 25) Reconhecer que a educação é ideológica; 26) Disponibilidade para o diálogo; e 27) Querer bem aos educandos.

A amarrar os dados anteriores, fica evidente quando se pergunta aos alunos: o que se espera de um 'bom monitor'? As palavras que mais suscitaram foram as que evocaram a característica relacional entre os alunos e seu tutor (Figura 3). Pouco se retrata sobre o conteúdo da disciplina, mas sobre o quanto 0 monitor compreenderá que o tempo do aluno para a construção do conhecimento difere da turma ('Paciência'; 'Disponibilidade'). 0 processo educativo deve ser reinventado na direção das forças sensíveis que o envolve (CABRAL, 2012). Quando o aluno quer 'Alegria' e 'Diálogo' ele quer tirar a disciplina de um campo técnico para um campo hermenêutico de 'Contextualização'.

\section{CONSIDERAÇÕES FINAIS}

O monitor complementa o docente, pois aplica saberes que o docente utiliza de forma insuficiente. Os saberes mais utilizados e requisitados ao monitor são aqueles que se referem à relação aluno-tutor e ao tempo de aprendizagem do aluno em relação a turma. Sendo assim, o monitor é uma importante parte no processo de ensino e aprendizagem, por seu paradidatismo. 
As possíveis limitações desse trabalho foram: i) a quantidade de carga horária da disciplina (30h), no qual o docente ficou limitado para aplicar todos os saberes; ii) diferentes $n$ amostral entre os grupos (duas turmas sem monitoria e oito com monitoria); iii) a disciplina de Introdução a Física, que é uma disciplina de exatas, possui conteúdos que os alunos de Biologia não possuem aptidão vocacional; iv) a heterogeneidade das turmas, os alunos que entram no primeiro semestre possuem rendimento diferenciado dos alunos do segundo semestre; e outros.

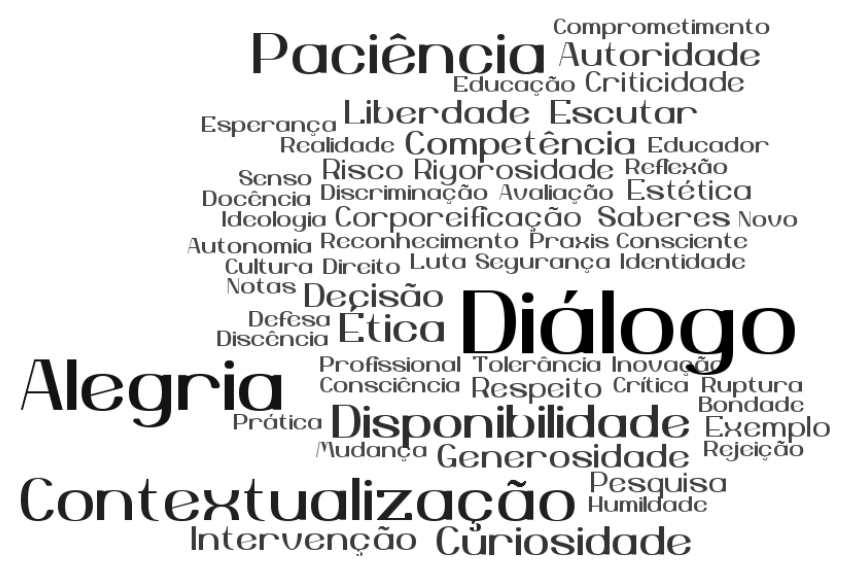

Figura 3. Nuvem de palavras formada a partir das respostas dos alunos sobre: o que se espera de um 'bom monitor'?

\section{REFERÊNCIAS}

CABRAL, M. S. A. Reinventando a educação: diversidade, descolonização e redes. Petrópolis/RJ: Editora Vozes Ltda, 2012. 279p.

DANTAS, O. M. Monitoria: fonte de saberes à docência superior. Revista Brasileira de Estudos Pedagógicos, v. 95, n. 241, p. 567589, 2014. DOI: 10.1590/S2176-6681/301611386.

ESKENAZI, E. S.; MARTINS, M. A.; FERREIRA JUNIOR, M. Teleeducação e monitoria ativa no ensino da saúde bucal a estudantes de medicina. Rev. bras. educ. med., v. 37 , n. 2, p. 235-244, 2013.

FREIRE, P. Pedagogia da autonomia: saberes à pratica educativa. 23. ed. São Paulo: Paz e Terra, 2002. 165 p.

FRISON, L. M. B. Monitoria: uma modalidade de ensino que potencializa a aprendizagem colaborativa e autorregulada. ProPosições, v. 27, n. 1, p. 133-153, 2016. DOI: 10.1590/01037307201607908.

GARCIA, L. T. S.; SILVA FILHO, L. G.; SILVA, M. V. G. Monitoria e avaliação formativa em nível universitário: desafios e conquistas. Perspectiva, v. 31, n. 03, 2013. DOI: 10.5007/2175795X.2013v31n3p973

HAAG, G. S. et al. Contribuições da monitoria no processo ensinoaprendizagem em enfermagem. Revista Brasileira de Enfermagem, v. 61, n. 2, p. $215-220$, 2008. DOI: 10.1590/S003471672008000200011.

SANTANA, O. A. Observação da Prática Docente: Um método para Licenciatura. Olinda: Livro Rápido, 2014. 50p. DOI: 10.12702/97885-406-0942-6

SANTANA, O. A. Evasão nas Licenciaturas das Universidades Federais: entre a apetência e a competência. Educação (UFSM), v. 41, n. 2, p. 311-328, 2016. DOI: 10.5902/1984644420199

SANTOS, A. R. et al. Ensino de Graduação e Inclusão Social: Uma experiência do Programa de Monitoria da UFOPA. Nuances, v. 26, n. 2, p. 53-73, 2015. DOI: 10.14572/nuances.v26i2.3303 